\title{
Acute Kidney Injury in Term Neonates
}

\author{
Juan C. Kupferman, $M D, M P H^{1, *}$ \\ Miheret Yitayew, $M D, M P H^{2}$ \\ Shantanu Rastogi, MD, MMM²
}

\author{
Address \\ ${ }^{*}, 1$ Division of Pediatric Nephrology and Hypertension, Maimonides Medical Center, \\ 977 48th Street, Brooklyn, NY, 11219, USA \\ Email: jkupferman@maimonidesmed.org \\ ${ }^{2}$ Division of Neonatology, Maimonides Medical Center, Brooklyn, NY, USA
}

Published online: 28 June 2018

C Springer International Publishing AG, part of Springer Nature 2018

Key points

- AKI is common in sick term/near-term newborns.

- Specific risk factors for AKI include perinatal asphyxia, complex cardiac surgery specially using cardiac bypass, ECMO, drug nephrotoxicity, and sepsis.

- Increased awareness and significance of neonatal AKI would lead to more prevention, faster recognition, and earlier treatment.

- Newer technology will be impacting earlier and more accurate diagnosis, management, and prognosis in the near future.

This article is part of the Topical Collection on Nephrology - Neonatal AKI

Keywords Acute renal failure $\cdot$ Acute renal insufficiency $\cdot$ Full-term $\cdot$ Newborn $\cdot$ Neonatal

\section{Abstract}

Purpose of Review The epidemiology of acute kidney injury (AKI) in the term/near-term newborn has not been previously thoroughly addressed. Therefore, we have focused our attention on the epidemiology of AKI in term/near-term neonates, including its prevention and management.

Recent Findings AKI occurs in a significant percentage of term/near-term babies presenting with perinatal asphyxia or undergoing cardiac surgery or extracorporeal membrane life support. Other important risk factors include neonatal sepsis and drug nephrotoxicity. Summary This review summarizes what is known about AKI in the term/near-term neonate and highlights applicability of current knowledge. New technologies (-omics) will provide important tools that may improve diagnosis and management of neonatal AKI.

\section{Introduction}

Acute kidney injury (AKI) is common in the neonatal intensive care unit (NICU) population, occurs in all gestational ages, and is associated with significant morbidity and mortality [1-5]. In the largest 
multicenter cohort study published to date, 30\% of sick infants admitted to a NICU across all gestational ages developed AKI [5]. Of note, 37\% of infants born at $\geq 36$ weeks had a diagnosis of AKI. Although studies have shown that sick term/near-term neonates are an important subset of the AKI population [5-16], a comprehensive description of the epidemiology of AKI in infants in this gestational age (GA) has not been previously performed.

Multiple risk factors place term/near-term neonates at risk of AKI, including perinatal asphyxia, complex cardiac surgery, extracorporeal membrane oxygenation
(ECMO), nephrotoxic medications, and sepsis [5-16]. AKI is a risk factor for chronic kidney disease (CKD) [17-22]. However, it is not known whether term/nearterm neonates are at increased risk of CKD. Multiple studies have also shown that infants who develop AKI have worse outcomes, including higher mortality rate [5, $7,8,11-16]$.

In this review, we summarize the epidemiology and risk factors for AKI, specifically in the term/near-term neonate, addressing current limitations of knowledge, and reviewing possible preventive and therapeutic measures.

\section{Definition of AKI}

AKI is an abrupt decrease in the kidneys ability to excrete waste products and maintain water and electrolyte hemostasis, due to a constellation of risk factors and etiologies that include intrinsic renal diseases, urinary tract abnormalities, extrarenal pathology, or other non-specific conditions.

Glomerular filtration rate (GFR) is the most commonly used measure of kidney function. GFR in term infants is very low and steadily increases in the first few days to weeks of life, as the kidneys assume their role in fluid and electrolyte regulation attaining adult levels by age 2 [23]. Serum creatinine (SCr) level is the most widely used biomarker to assess kidney function; its use in the neonatal population has unique challenges [24]. Initial SCr levels are a reflection of maternal creatinine rather than the neonate's. There is a decline in SCr level in the first days to weeks of life, and this rate of decline depends on the gestational age at birth.

Criteria for defining AKI has evolved from an arbitrary use of absolute SCr cut-offs to a more structured guideline that combines small percentage changes in SCr and urine output leading to a better comparison of data from several studies (Table 1) [2, 25-28]. Jetton et al. have recently proposed a neonatal definition to provide a more standardized definition for the neonatal population [2]. This modified definition relies on a previous lowest SCr levels as the reference value, from which absolute rise is compared. It identifies three levels of AKI severity based on changes in urine output and SCr level. A SCr level of $2.5 \mathrm{mg} / \mathrm{dl}$ was included as the cut-off to define stage $3 \mathrm{AKI}$ as it reflects a GFR of $<10 \mathrm{ml} / \mathrm{min} / 1.73 \mathrm{~m} 2$ at this age. Validation of the latest neonatal AKI definition and/or development of novel definitions, which use meaningful outcomes to validate the optimal SCr and urine output thresholds, should be an area of further research in the NICU population [28].

\section{Epidemiology and risk factors}

The incidence of neonatal AKI (nAKI) has been reported to vary widely depending on whether the study population included the whole NICU population, a specific gestational age or whether specific subgroups of sick neonates 
Table 1. Staging criteria for neonatal acute kidney injury

\begin{tabular}{|c|c|c|}
\hline Stage of AKI & Serum creatinine & Urine output \\
\hline \multicolumn{3}{|l|}{ AKIN } \\
\hline 1 & $\mathrm{SCr} 1.5$-fold baseline or $\geq 0.3 \mathrm{mg} / \mathrm{dl}$ increase & $<0.5 \mathrm{ml} / \mathrm{kg} / \mathrm{h}$ for $\geq 6 \mathrm{~h}$ \\
\hline 2 & SCr 2-fold baseline & $<0.5 \mathrm{ml} / \mathrm{kg} / \mathrm{h}$ for $\geq 12 \mathrm{~h}$ \\
\hline 3 & $\begin{array}{l}\mathrm{SCr} 3 \text {-fold baseline or increase in } \mathrm{SCr} \text { to } \geq 4.0 \mathrm{mg} / \mathrm{dl} \\
\text { with an acute increase of } \geq 0.5 \mathrm{mg} / \mathrm{dl} \text { or RRT }\end{array}$ & $<0.3 \mathrm{ml} / \mathrm{kg} / \mathrm{h}$ for $\geq 24 \mathrm{~h}$ or anuria for $\geq 12 \mathrm{~h}$ \\
\hline \multicolumn{3}{|c|}{ 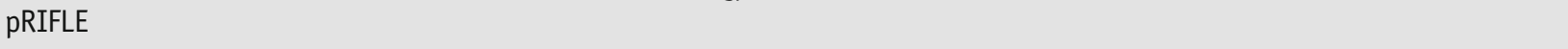 } \\
\hline $\mathrm{R}$ & eGFR decrease $>25 \%$ & $<0.5 \mathrm{ml} / \mathrm{kg} / \mathrm{h}$ for $\geq 8 \mathrm{~h}$ \\
\hline I & eGFR decrease $>50 \%$ & $<0.5 \mathrm{ml} / \mathrm{kg} / \mathrm{h}$ for $\geq 16 \mathrm{~h}$ \\
\hline $\mathrm{F}$ & eGFR decrease $>75 \%$ or $<35 \mathrm{ml} / \mathrm{min} / 1.73 \mathrm{~m}^{2}$ & $<0.3 \mathrm{ml} / \mathrm{kg} / \mathrm{h}$ for $\geq 24 \mathrm{~h}$ or anuric for $\geq 12 \mathrm{~h}$ \\
\hline $\mathrm{L}$ & Failure $>4$ weeks & \\
\hline E & Failure $>3$ months & \\
\hline \multicolumn{3}{|l|}{ Neonatal KDIGO } \\
\hline 1 & $\mathrm{SCr} 1.5$-fold baseline or $\geq 0.3 \mathrm{mg} / \mathrm{dl}$ increase & $<0.5 \mathrm{ml} / \mathrm{kg} / \mathrm{h}$ for $6-12 \mathrm{~h}$ \\
\hline 2 & SCr 2-fold baseline & $<0.5 \mathrm{ml} / \mathrm{kg} / \mathrm{h}$ for $\geq 12 \mathrm{~h}$ \\
\hline 3 & $\begin{array}{l}\mathrm{SCr} 3 \text {-fold baseline or increase in } \mathrm{SCr} \text { to } \geq 2.5 \mathrm{mg} / \mathrm{dl} \\
\text { with an acute increase of } \geq 0.5 \mathrm{mg} / \mathrm{dl} \text { or RRT }\end{array}$ & $<0.3 \mathrm{ml} / \mathrm{kg} / \mathrm{h}$ for $\geq 24 \mathrm{~h}$ or anuria for $\geq 12 \mathrm{~h}$ \\
\hline
\end{tabular}

with additional comorbidities are studied [5-16]. In a recent multicenter cohort study that included neonates admitted to level 2-4 NICUs at 24 medical centers during a 3-month period and who received intravenous fluids for at least $48 \mathrm{~h}$, we can see how the incidence of AKI differs across the GA continuum. Differences in the incidence of nAKI occurred in a U distribution $(\leq 29$ weeks GA $=$ $45 \%$; $\geq 29-36$ weeks $\mathrm{GA}=14 \% ;>36$ weeks $\mathrm{GA}=41 \%$ ). Even after controlling for multiple confounders, infants between 29 and 36 weeks GA were more likely to die (adjusted OR $=5.1(1.6-6.5) p<0.01$ ) and had longer 9.6 more adjusted days compared to those without AKI. Similarly, even after controlling for multiple confounders, infants $>36$ weeks GA were more likely to die (adjusted OR $=3.9(1.2-13.2) p<0.05)$ and had longer 11 more adjusted hospital days compared to those without AKI.

\section{Risk factors for AKI in term/near-term neonates}

Even with a full set of nephrons and a more mature renal tubular function, newborns born at term may develop certain comorbidities that could place them at increased risk. Significant risk factors include perinatal asphyxia, complex cardiac surgery, ECMO, nephrotoxic medications, and sepsis (Table 2) [516]. Term/near-term babies with AKI were more likely to have been born outside the hospital, to mothers with maternal infection, with meconiumstained fluid, and with higher rates of hypoxic-ischemic encephalopathy [5]. 


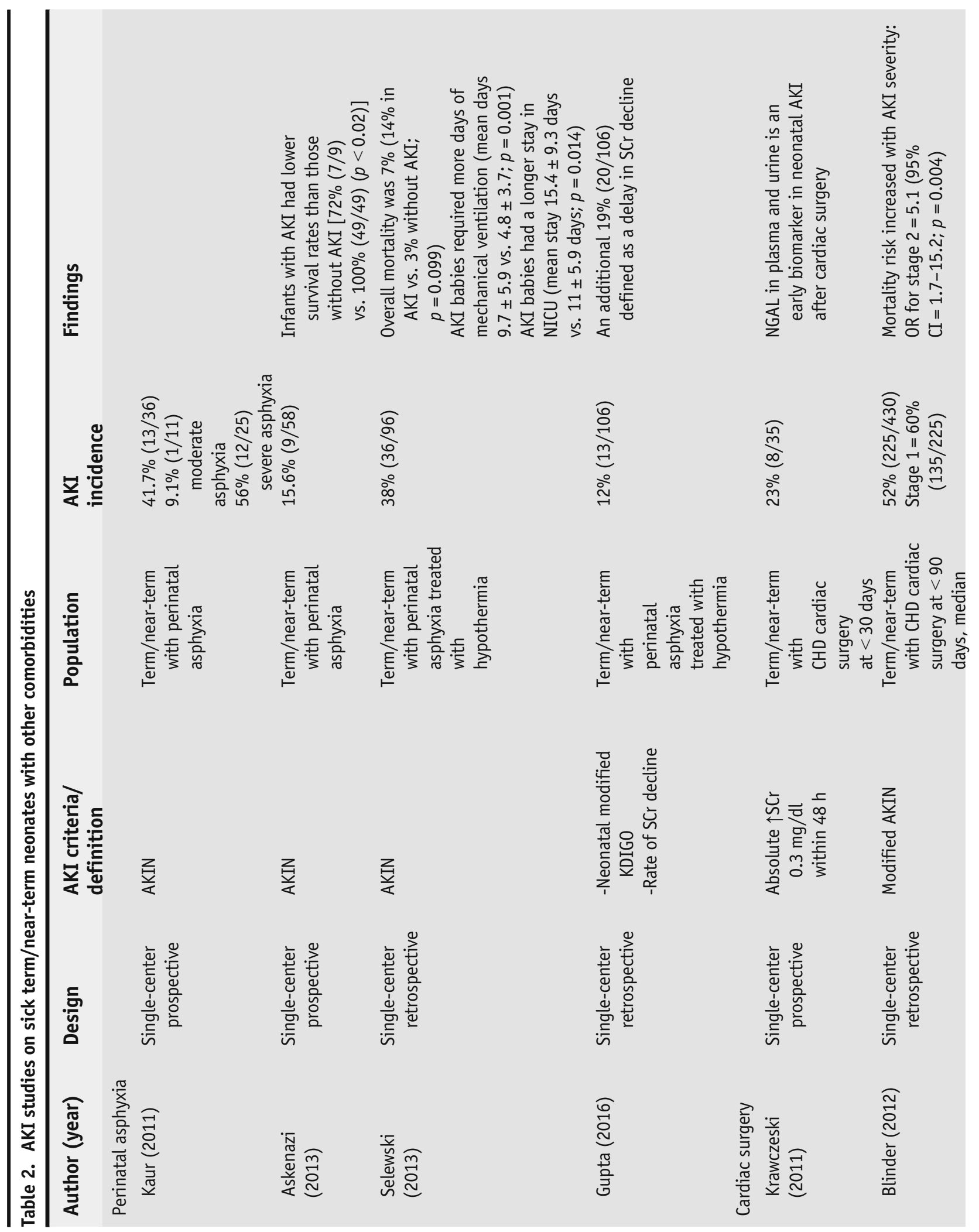




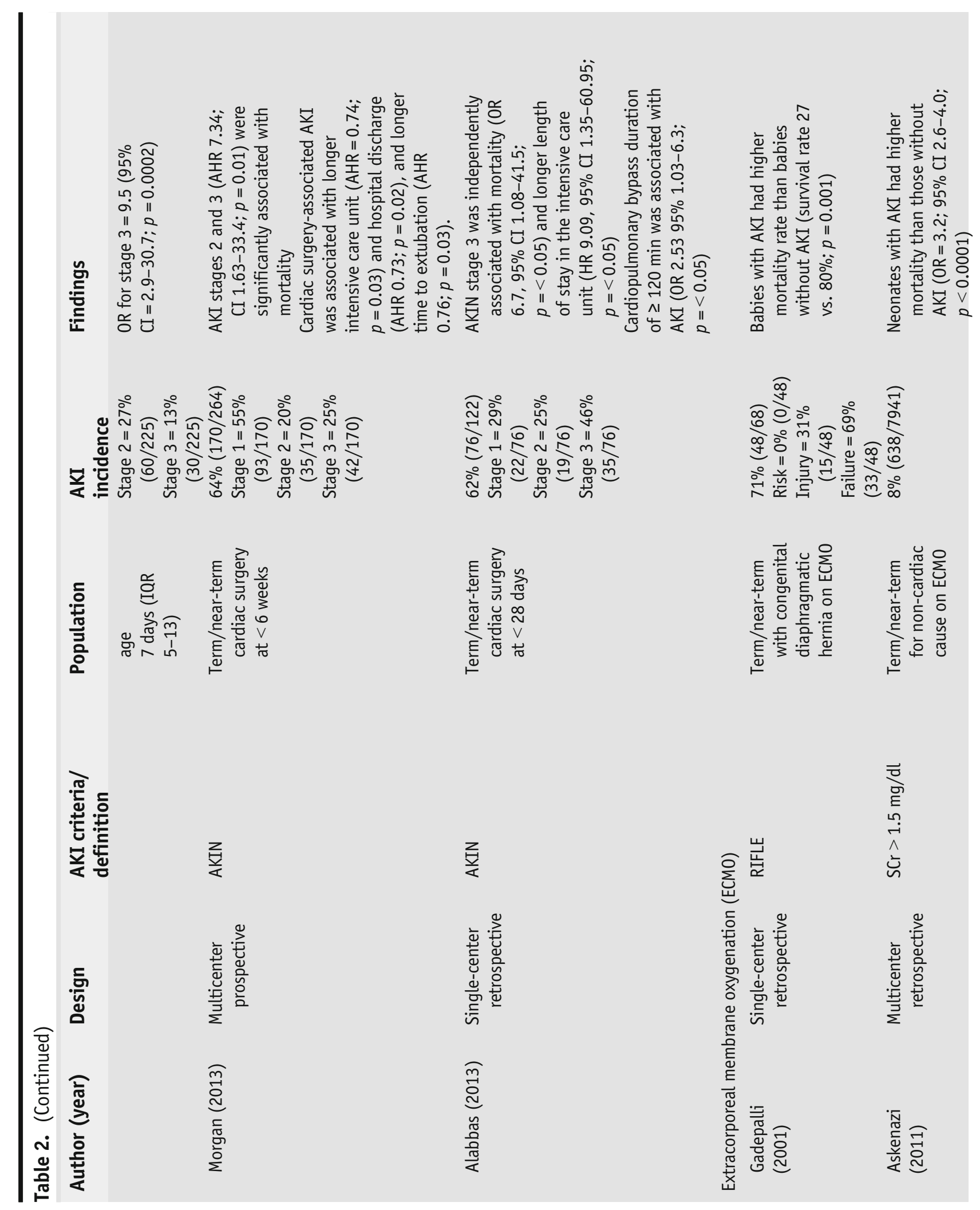




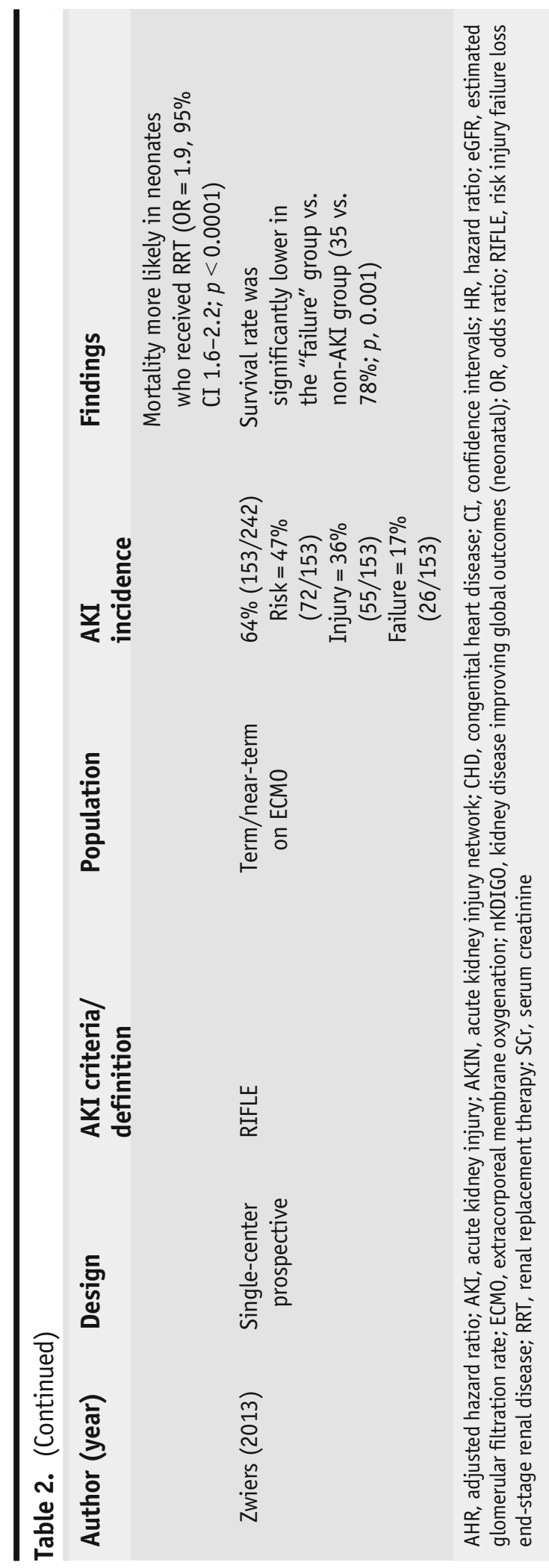




\section{Perinatal asphyxia}

Several studies have focused on a particular near-term/term population of neonates. Below, we present epidemiology data on neonates born with asphyxia, and on those who undergo cardiopulmonary bypass surgery and/or extracorporeal membrane oxygenation.

Asphyxia remains a significant cause of morbidity and mortality in the term/near-term neonate [29]. The incidence of AKI in studies of asphyxiated infants varied from 12 to $42 \%$, with higher incidence in sicker babies. In this population, AKI was associated with increased mortality. Kaur et al. [6] evaluated 36 neonates $\geq 34$ weeks gestation with 1 min Apgar score $<7$. AKI developed in $9.1 \%$ of infants with moderate asphyxia and in 56\% with severe asphyxia.

Askenazi et al. [7] studied a cohort of neonates with GA $>34$ weeks and birth weight $>2000 \mathrm{~g}$, and 5-min Apgar scores $<7$. AKI was defined as a rise in $\mathrm{SCr}>$ $0.3 \mathrm{mg} / \mathrm{dl}$ or a persistent $\mathrm{SCr}>1.5 \mathrm{mg} / \mathrm{dl}$. AKI was defined as a rise in $\mathrm{SCr}>$ $0.3 \mathrm{mg} / \mathrm{dl}$ or a persistent $\mathrm{SCr}>1.5 \mathrm{mg} / \mathrm{dl}$. AKI was associated with higher birth weight; infants with AKI had increased risk of mortality. Selewski et al. [8] reported the first study of neonates with perinatal asphyxia that received therapeutic hypothermia. GA was $39 \pm 1.6$ weeks in the group that developed AKI; GA was similar for all asphyxiated babies overall $(39 \pm 1.6 ; p=0.91)$. Neonates with AKI required more days of mechanical ventilation, had longer length of stay in NICU, and had higher mortality.

In a study of term babies with perinatal asphyxia treated with hypothermia for hypoxic-ischemic encephalopathy, Gupta et al. [9] challenged the KDIGO neonatal AKI definition.

Because a healthy term neonate with normal kidney function should have a steady decline in SCr after birth, the absence of this normal trajectory could signify a substantial renal injury. Gupta et al. compared clinical parameters (i.e., hemodynamic support) and kidney injury biomarkers among three groups of infants: (1) infants with nAKI ( $\mathrm{SCr} \geq 0.3 \mathrm{mg} / \mathrm{dL}$ ), (2) infants whose SCr trajectories did not drop as expected, and (3) infants with normal SCr trajectories. They showed that infants with abnormal SCr trajectories were more similar to those with nAKI than to those who had normal SCr trajectory. This suggests that term infants with an abnormal SCr decline, or any SCr increase, during the first postnatal week, may represent a significant kidney injury.

AKI is a frequent complication after cardiac surgery in term/near-term babies with a reported incidence varying from 23 to $64 \%$ [10-13]. Krawczeski et al. [10] reported an incidence of $23 \%$ in a study evaluating the use of neutrophil gelatinase-associated lipocalin (NGAL) to predict postoperative AKI in 35 neonates $>37$-week gestation with congenital heart disease (CHD) without urinary tract abnormalities. There was no difference in mortality rates between those with and without AKI [10]. Blinder et al. [11] reviewed charts of infants $\geq 34$ weeks who underwent surgery for CHD at their institution. Most infants were term/near-term based on patient's median weight and interquartile range at surgery of $3.1 \mathrm{~kg}(2.8-3.5 \mathrm{~kg})$ [11]. In contrast to the previous study, postoperative AKI was associated with longer ICU stay (for all three stages of AKI), increased risk of prolonged mechanical ventilation (for stages 2 and 3 
AKI), and increased risk of mortality 12 vs. $3 \%(p=0.001)$. Morgan et al. [12] evaluated data from a prospective cohort study of 264 neonates with a mean GA of $38.8 \pm 1.9$ weeks who underwent cardiac surgery in the first 6 weeks of life. Almost 2/3 (64\%) of infants developed AKI. Post-cardiac surgery AKI was an independent risk factor for worse outcomes, including mortality. AlAbbas et al. (13) examined charts of neonates $\leq 28$ days of age who underwent cardiac surgery. Of 76 babies with AKI, 90\% were term neonates. Severe AKI (AKIN stage 3) was independently associated with mortality and longer length of stay in the NICU.

\section{Extracorporeal membrane oxygenation}

ECMO is an advanced cardiopulmonary bypass support indicated for reversible cardiovascular or respiratory failure refractory to conventional therapy.

Newborns who receive ECMO are at increased risk for AKI [14-16], with a reported incidence varying from $8 \%$ in the Extra Corporeal Life Support Organization (ESLO) registry up to $71 \%$ in babies with diaphragmatic hernia requiring ECMO. Term/near-term neonates are at particularly increased risk of AKI, as ECMO support by criterion is indicated for neonates $>34$ weeks GA. Gadepalli et al. [14] reviewed charts of term/near-term patients with congenital diaphragmatic hernia that required ECMO. There was no difference in mean GA in babies with and without AKI. Neonates that qualified for RIFLE classification of "failure" spent more time on a ventilator and on extracorporeal support and had an increased mortality rate. Askenazi et al. [15] examined data from the ESLO registry and assessed the impact of AKI in neonates who received ECMO for non-cardiac reasons. Of the 7941 sick neonates in the registry, $2175(27.4 \%)$ died. Non-survivors were more likely to have AKI ( 19 vs. $3.9 \% ; p=0.0001$ ). AKI independently predicted mortality in neonates who received ECMO after adjusting for other known predictors of mortality. Zwiers et al. [16] evaluated data of full-term neonates $<28$ days who received ECMO at a single center. About 2/3 of babies developed AKI. Younger age at the start of ECMO was a significant predictor of AKI $(p=0.004)$. In addition, AKI was associated with increased risk of mortality.

Sepsis is one of the most common diagnoses in term/near-term neonates admitted to the NICU. Neonatal sepsis in term/near-term neonates could develop due to perinatal risk factors or related to nosocomial infection among those who undergo surgeries. The predisposition to AKI in the septic newborn may result from a myriad of factors, ranging from direct damage to the kidneys associated with local infection to general effects on the body by the sepsis and its associated complications. Sepsis-associated hypotension can lead to decreased renal blood flow and compromise tubular functions. Disseminated intravascular coagulopathy may further damage the organ by either thrombosis of the renal vessels or by microthrombi leading to damage of the microvasculature of the organ. Further infections of distant organs, such as brain or adrenals, can lead to tubular dysfunction due to inappropriate ADH secretion, or to fluid and electrolyte imbalance and hypotension [30].

Recently, it has been demonstrated that inflammatory mediators released during infection may lead to cell cycle arrest and tubular dysfunction and trigger 
AKI [30]. The relationship of sepsis and AKI is bidirectional and related by the common thread of immunomodulation and pro-inflammatory state. Sepsis and AKI were independently associated with mortality [31]. No neonatal studies have been done to specifically address AKI in sepsis for pathophysiology and intervention.

\section{Identification of the etiology}

The use of nephrotoxic medications in the NICU is very common and include antibacterials (i.e., aminoglycosides and vancomycin), antivirals (i.e., acyclovir), antifungals (i.e., amphotericin A), non-steroidal anti-inflammatory agents (i.e., indomethacin and ibuprofen), and antihypertensives/afterload reducing agents (i.e., angiotensin-converting enzyme [ACE] inhibitors). Each group will damage the kidneys by different mechanisms, affecting renal blood flow, glomerular filtration, tubular function, or the interstitium, all resulting in a common pathway of AKI (Fig. 1) [32, 33].

Aminoglycosides (i.e., gentamycin), the mainstay of treatment of neonatal sepsis, cause tubular cell death through inhibition of lysosomal phospholipase, cellular lysosomal accumulation, and membrane disruption, leading to cell death [34]. Vancomycin, an anti-staphylococcal agent, causes renal tubular ischemia by its oxidative effects on the proximal tubule [35]. Acyclovir, an antiviral for herpes simplex infection, is relatively insoluble in urine, leading to crystallization and tubular obstruction [36]. It may also cause direct damage to renal tubular cells [37]. The antifungal Amphotericin A causes direct distal tubular toxicity, by increasing tubular membrane permeability, resulting in renal tubular acidosis and electrolyte disturbances [38]. Anti-inflammatory agents (i.e., indomethacin and ibuprofen), utilized to close a patent ductus arteriosus, block cyclooxygenase and prostaglandin synthase leading to vasoconstriction [39]. ACE inhibitors (i.e., enalapril), indicated for cardiac dysfunction or hypertension, may decrease renal perfusion by inhibiting vasoconstriction of the efferent arteriole, resulting in a drop in GFR [40].

Although how to define nAKI is a topic of much discussion in the literature, the classic classification according to location of the primary event affecting the kidneys, as prerenal, renal, or post-renal AKI, is useful for clinical purposes, as it may determine the course of action in terms of management. The incidence of each type will vary depending on the complexity of NICU services, availability of neonatal cardiac surgery and ECMO, whether it occurs in a developed or developing country, and other factors.

Although reported to be the most common type of AKI, the incidence will vary widely depending on the factors outlined above. Prerenal AKI occurs when there is decreased perfusion to the kidneys. Causes of renal hypoperfusion in term neonates are similar to other gestational ages and include increased fluid loss or blood loss, third spacing, sepsis, congestive heart failure, and medications decreasing renal blood flow and/or blood pressure. 


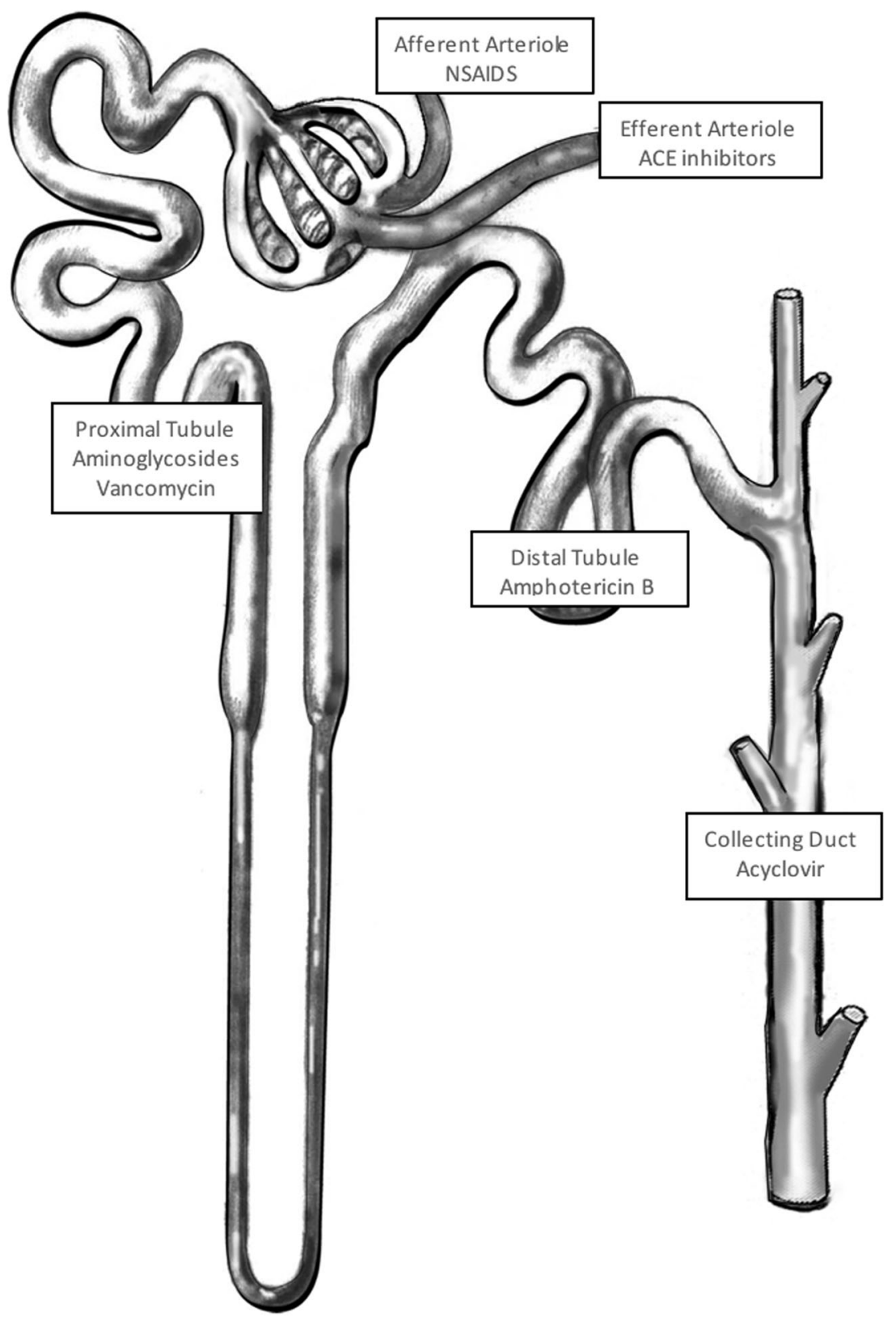

Fig. 1. Main site of action of nephrotoxic medications causing AKI in term/near-term newborns. NSAIDS, non-steroidal antiinflammatory drugs. ACE, angiotensin-converting enzyme.

\section{Renal AKI}

Intrinsic kidney injury can occur by different mechanisms. Any entity that causes prolonged hypoperfusion of the kidneys can cause renal ischemic injury 


\section{Post-renal AKI}

with renal tubular injury. Tubular damage, including tubular obstruction, can occur secondary to drug nephrotoxicity. Renal vascular compromise, such as bilateral renal venous and artery thrombosis, can cause renal AKI. In contrast to older children, primary glomerular disease is infrequent in the neonatal age.

Urinary tract obstruction causes retention of the urine flow, increasing tubular pressure and decrease in GFR. Important etiologies in term/near-term newborns include posterior urethral valves (PUV) in males, bilateral ureteropelvic obstruction, neurogenic bladder, or external obstruction from compression by a tumor. Renal ultrasonography will show signs of obstruction, such as hydronephrosis, ureteral dilatation, or hypertrophied bladder wall.

\section{Prevention and treatment}

Although there are no specific interventions to prevent or treat AKI in term/nearterm neonates, some general measures can be recommended, including preservation of adequate renal perfusion, maintenance of fluid and electrolyte balance, avoidance or monitoring blood concentrations of nephrotoxic medications, relief of pressure caused by urinary obstruction, and relief of abdominal pressure in the event of abdominal compartment syndrome [41].

It is important to maintain a normal blood pressure in order to preserve renal perfusion. Renal perfusion is clinically assessed by measuring urine output, and biochemically by measuring blood urea nitrogen and SCr. Abnormalities in any of these parameters would prompt the clinician to increase fluid intake or to consider the prudent use of vasopressors. The use of low-dose dopamine $(<5 \mu)$ $\mathrm{kg} / \mathrm{min}$ ) may help in renal vasodilation and maintain adequate renal perfusion, despite the lack of conclusive data supporting its use [42]. Early intervention to restore intravascular volume and/or cardiac output leading to adequate renal blood flow is critical to improve urine output and prevent renal parenchymal damage [43]. Importantly, the blood pressure that is needed to perfuse the kidneys adequately may differ under different clinical scenarios-for example, if there is relatively low oncotic pressure and high intra-abdominal pressure, the required perfusion pressure needed to adequately perfuse the neonate maybe higher than in normal situations.

Close observation of fluid intake and output should be maintained, as negative fluid balance may aggravate AKI by decreasing renal perfusion, and a positive fluid balance is associated with detrimental outcomes, including prolonged ventilatory support and hospital stay [44]. This balancing act is difficult, but critical, in both preserving renal perfusion and preventing renal dysfunction associated with fluid overload. The difficulty in neonates is associated with the inability to restrict water for oliguric renal failure, as an obligate amount of fluid is required to administer for the provision of nutrition, blood and blood 
products, and medications, along with insensible water loss. Diuretics are routinely used in fluid overloaded oliguric neonate, despite undocumented benefit. A lack of response to diuretics may predict worsening AKI and may need renal replacement therapy (RRT) [45].

Hyponatremia may be due to either fluid retention associated with fluid overload or to excessive tubular sodium loss. The underlying mechanism should be differentiated as the management of these two etiologies differ considerably. Excessive weight gain with poor urine output, especially in a clinical scenario of a prerenal damage, would point towards fluid retention. This is managed by fluid restriction if the serum sodium $>110 \mathrm{mEq} / \mathrm{L}$ and baby is asymptomatic, or with the use of hypertonic saline if the baby is symptomatic and/or the serum sodium $<110 \mathrm{mEq} / \mathrm{L}$. If there is excessive urine output and increased tubular sodium loss, it is managed by fluid replacement and increased enteral or parenteral sodium intake.

Management of severe hyperkalemia requires calcium administration to stabilize the myocardium, followed by medications that shift extracellular potassium to the intracellular compartment, such as bicarbonate, glucose insulin drip, and inhaled beta agonists. Decreasing total body potassium can be accomplished by increasing urinary excretion with the use of loop diuretics and/ or decreasing enteral absorption utilizing cation exchange resins or decanting milk to reduce its potassium content [46].

Hyperphosphatemia is associated with renal dysfunction and is corrected by decreasing the intake of phosphate utilizing a low phosphate formula or the use of calcium as phosphate binder in the intestine. Furthermore, increase in calcium intake and increasing serum calcium concentration may suppress serum phosphate level.

\section{Avoiding or monitoring exposure to nephrotoxic drugs}

Drug nephrotoxicity is a potentially preventable cause of AKI. Avoidance or the cautious use of nephrotoxic medications will decrease the risk of drug-induced AKI. Serum concentrations should be measured and the dose and interval adjusted. Other contributing factors, which may increase drug toxicity, including length of treatment, presence of other nephrotoxic agents, and other associated comorbidities that compromise baseline renal function, should be also assessed.

When post-renal AKI is suspected, prompt evaluation and recognition of urinary obstruction by ultrasonography is crucial. Prompt relief of the obstruction will usually result in restoration of renal function. Obstruction may be relieved by bladder catheterization, endoscopic ablation of PUV, or other urological procedures, such as vesicostomy. However, chronic damage may persist over time in many cases of PUV, due to previous injury caused by prolonged intrauterine urinary obstruction $[47,48]$.

\section{Renal replacement therapy}

RRT is indicated in severe cases of neonatal AKI with fluid overload, and/or electrolyte abnormalities, such as hyperkalemia, hyponatremia, 


\section{Evolving therapies for prevention and/or management pediatric RRT registry [51].}

\section{Theophylline and caffeine}

hyperphosphatemia or metabolic acidosis, refractory to conservative management, or in need of parenteral nutrition [49-52]. There are two modalities for neonates with AKI. Because of relative simplicity, peritoneal dialysis (PD) is the modality of choice in this age group $[50,53]$. There is no need for vascular access or extracorporeal circuit; it requires the placement of a $\mathrm{PD}$ catheter in the abdomen. When PD is not a viable option or not effective (i.e., abdominal wall defects, skin infections, etc.), CRRT can be performed as well. CRRT is technically more difficult and requires vascular access and an extracorporeal circuit. Most CRRT machines are not designed for neonates; however, newer machines have been specifically designed for use in neonates (not yet available in the USA) [49, 54].

One machine currently being used in neonates in the USA is the Aquadex machine that has been adapted for use as CRRT in neonates [55]. These machines have much smaller extracorporeal volumes than conventional dialysis machines and promise to substantially decrease the complexity and risk associated with CRRT in neonates.

RRT is infrequently utilized in neonatal AKI. The multicenter AWAKEN study reported that RRT was performed in only 4\% (25/605) neonates with AKI, which accounted to $1 \%(25 / 2022)$ of enrolled neonates and $<0.5 \%$ of the infants admitted to the NICU during AWAKEN screening. CRRT was performed in 16 cases (four alone, 11 along with ECMO, and one along with PD) and PD alone in nine cases. Babies that underwent RRT had a survival rate of 76\% (19/ 25 ), better than the $44 \%$ survival rate in infants $<5 \mathrm{~kg}$ reported in a large

Theophyline has been studied in multiple randomized placebo-controlled studies administered during the first hours of life in asphyxiated neonates. Those who received theophyline had increased urine output and lower SCr than those randomized to placebo $[4,56,57]$. It attenuates the afferent arteriole constriction and decreased glomerular blood flow caused by adenosine. Recently, caffeine (a different methylxanthine with less side effects than theophyline) has been shown to be independently associated with a decreased incidence of AKI in preterm neonates [58].

\section{Dexmedetomidine}

Its use in children undergoing cardiovascular surgery demonstrated a decrease in the incidence of AKI from 36 to $24 \%$ ( $p=0.046$ ) [59]. Its anti-inflammatory, sympatholytic, and cytoprotective effects, along with reduction of endothelin 1 and renin, may explain its renoprotective effects [60]. There are no studies in neonates, and therefore, it is not recommended at this time.

This is a selective dopamine 1 receptor agonist, which causes a dose-dependent natriuresis and increase in renal blood flow [61]. Its use in infants (including neonates) in the first few months of life undergoing cardiac surgery showed 
decrease in biochemical measures of AKI and decrease use of vasopressors and diuretics [62].

Hydrocortisone showed decreased need for vasopressors and higher urine output among neonates undergoing cardiopulmonary bypass [63, 64]. The mechanism is unclear, but it appears to be related to its anti-inflammatory effects. More studies are needed, especially in term neonates with AKI associated with sepsis and asphyxia before they can be recommended for clinical use.

Free plasma hemoglobin in adults who undergo cardiopulmonary bypass has been associated with AKI through lipid peroxidation and oxidative injury. Acetaminophen has been found to attenuate this effect in adults; however, this has not been studied in the pediatric population [65].

Some infants develop hyperuricemia associated with dehydration, sepsis with multiple organ failure, and asphyxia. This increase in uric acid causes acute tubular injury leading to AKI. Rasburicase is a recombinant urate oxidase enzyme that effectively oxidizes uric acid to allantoin, which is readily excretable and highly water-soluble. It has advantages over allopurinol, as the latter prevents formation of uric acid but does not decrease preexisting uric acid. Also, rasburicase does not increase precursors of uric acid, which can themselves cause AKI. Furthermore, rasburicase has been shown to be safe from experience with treatment of children with tumor lysis syndrome [66].

\section{Preventive use of peritoneal dialysis}

The use of PD may be useful to decrease fluid overload and improve the outcome of critically sick neonates. A prospective study in children undergoing cardiopulmonary bypass demonstrated negative fluid balance and increased urine output [67]. PD may decrease inflammatory mediators, such as IL-6, IL-8, and IL-10 [68, 69].

\section{Other experimental therapies}

The use of alkaline phosphatase is being investigated for the treatment of sepsisrelated AKI [27]. Erythropoietin has been tested in vitro, due to its ability to decrease apoptotic cell death. Other suggested therapies include scavenging nitric oxide with methylene blue and reducing nitric oxide associated proximal tubular injury; use of vitamin $\mathrm{D}$, which acts by altering inflammatory response through immunomodulation and targeted inhibition of pro-inflammatory cytokines.

\section{Remote ischemic preconditioning}

Remote ischemic preconditioning (RIPC) is a process where transient brief episodes of ischemia are applied to the patient and are protective from a subsequent prolonged or severe ischemia and its associated organ damage [70]. RIPC before cardiac surgery may help in attenuating renal damage associated with this procedure. This protection occurs by inducing the release of signaling 
molecules that activate Toll-like receptors in the proximal tubule epithelia, conditioning the epithelium and leading to tolerance of subsequent inflammatory or ischemic stress.

\section{Particle-retentive in-line filtration}

Particles from infusion therapy may aggravate the inflammatory response from cardiopulmonary bypass, predisposing to thrombosis, impaired microcirculation, and immune response associated with AKI. In-line filters incorporated into infusion lines retain particles and almost completely prevent particle infusion and its subsequent organ damage. There was a $10-15 \%$ reduction of AKI after cardiac surgery in a randomized control trial using in-line filters from absolute risk of $40 \%$ AKI in patients undergoing cardiac bypass without in-line filters [71]. No studies exist in the pediatric population.

\section{Recent omics studies and its impact on diagnosis, prognosis, and management}

\section{Conclusions}

Omics refers to the technologies that collect information and functions of genes (genomics), mRNA (transcriptomics), proteins (proteomics), and metabolites (metabolomics) in a biological sample $[72,73]$. The use of novel urinary biomarkers, such as kidney injury molecule-1, neutrophil gelatinase-associated lipocalin (NGAL), and N-acetyl-D-glucosaminidase, has shown promise as early indicators of both kidney injury and impaired kidney function in neonates [74]. In addition, urinary biomarkers have been identified using proteomics that could predict the outcome of ureteropelvic junction obstruction [75]. Despite the growing number of studies that looked at the application of urine biomarkers to detect neonatal AKI, these biomarkers are not yet ready for clinical use.

AKI is common in the NICU population. This review specifically addressed the epidemiology of AKI in term/near-term neonates. Risk factors include perinatal asphyxia, complex cardiac surgery, ECMO, nephrotoxic medications, and sepsis.

Prevention of AKI involves addressing the risk factors mentioned above and maintaining adequate renal perfusion, preventing fluid overload and electrolytes imbalance. Treatment is conservative in most cases. RRT is a valid option for the sickest babies. Newer technologies will hopefully provide earlier and more accurate diagnosis and improve management of neonatal AKI.

\section{Compliance with Ethical Standards}

\section{Conflict of Interest}

Juan C. Kupferman reports speaker's fees from Alexion Pharmaceuticals, unrelated to the submitted work.

Miheret Yitayew declares that she has no conflict of interest.

Shantanu Rastogi declares that he has no conflict of interest. 
1. Askenazi DJ, Ambalavanan N, Goldstein SL. Acute kidney injury in critically ill newborns: what do we know? What do we need to learn? Pediatr Nephrol. 2009;24(2):265-74.

2. Jetton JG, Askenazi DJ. Update on acute kidney injury in the neonate. Curr Opin Pediatr. 2012;24(2):191-6.

3. Jetton JG, Askenazi DJ. Acute kidney injury in the neonate. Clin Perinatol. 2014;41(3):487-502.

4. Selewski DT, Charlton JR, Jetton JG, Guillet R, Mhanna MJ, Askenazi DJ, et al. Neonatal acute kidney injury. Pediatrics. 2015;136(2):e463-73.

5. Jetton JG, Louis J, Boohaver M, Sethi SK, Wazir M, Rohatgi S, et al. Incidence and outcomes of neonatal acute kidney injury (AWAKEN): a multicentre, multinational, observational cohort study. Lancet Child Adolescent Health. 2017:184-94.

6. Kaur S, Jain S, Saha A, Chawla D, Parmar VR, Basu S, et al. Evaluation of glomerular and tubular renal function in neonates with birth asphyxia. Ann Trop Paediatr. 2011;31(2):129-34.

7. Askenazi DJ, Koralkar R, Hundley HE, Montesanti A, Patil N, Ambalavanan N. Fluid overload and mortality are associated with acute kidney injury in sick near-term/ term neonate. Pediatr Nephrol. 2013;28(4):661-6.

8. Selewski DT, Jordan BK, Askenazi DJ, Dechert RE, Sarkar S. Acute kidney injury in asphyxiated newborns treated with therapeutic hypothermia. J Pediatr. 2013;162(4):725-9.e1

9. Gupta C, Massaro AN, Ray PE. A new approach to define acute kidney injury in term newborns with hypoxic ischemic encephalopathy. Pediatr Nephrol. 2016;31(7):1167-78.

10. Krawczeski CD, Woo JG, Wang Y, Bennett MR, Ma Q, Devarajan P. Neutrophil gelatinase-associated lipocalin concentrations predict development of acute kidney injury in neonates and children after cardiopulmonary bypass. J Pediatr. 2011;158(6):1009-15.e1

11. Blinder JJ, Goldstein SL, Lee VV, Baycroft A, Fraser CD, Nelson D, et al. Congenital heart surgery in infants: effects of acute kidney injury on outcomes. J Thorac Cardiovasc Surg. 2012;143(2):368-74.

12. Morgan CJ, Zappitelli M, Robertson CM, Alton GY, Sauve RS, Joffe AR, et al. Risk factors for and outcomes of acute kidney injury in neonates undergoing complex cardiac surgery. J Pediatr. 2013;162(1):120-7.e1

13. Alabbas A, Campbell A, Skippen P, Human D, Matsell D, Mammen C. Epidemiology of cardiac surgeryassociated acute kidney injury in neonates: a retrospective study. Pediatr Nephrol. 2013;28(7):1127-34.

14. Gadepalli SK, Selewski DT, Drongowski RA, Mychaliska GB. Acute kidney injury in congenital diaphragmatic hernia requiring extracorporeal life support: an insidious problem. J Pediatr Surg. 2011;46(4):630-5.

15. Askenazi DJ, Ambalavanan N, Hamilton K, Cutter G, Laney D, Kaslow R, et al. Acute kidney injury and renal replacement therapy independently predict mortality in neonatal and pediatric noncardiac patients on extracorporeal membrane oxygenation. Pediatr Crit Care Med. 2011;12(1):e1-6.

16. Zwiers AJ, de Wildt SN, Hop WC, Dorresteijn EM, Gischler SJ, Tibboel D, et al. Acute kidney injury is a frequent complication in critically ill neonates receiving extracorporeal membrane oxygenation: a 14-year cohort study. Crit Care. 2013;17(4):R151.

17. Mammen C, Al Abbas A, Skippen P, Nadel H, Levine D, Collet JP, et al. Long-term risk of CKD in children surviving episodes of acute kidney injury in the intensive care unit: a prospective cohort study. Am J Kidney Dis. 2012;59(4):523-30.

18. Chawla LS, Eggers PW, Star RA, Kimmel PL. Acute kidney injury and chronic kidney disease as interconnected syndromes. N Engl J Med. 2014;371(1):58-66.

19. Askenazi DJ, Morgan C, Goldstein SL, Selewski DT, Moxey-Mims MM, Kimmel PL, et al. Strategies to improve the understanding of long-term renal consequences after neonatal acute kidney injury. Pediatr Res. 2016;79(3):502-8.

20. Zwiers AJ. H IJ, van Rosmalen J, Gischler SJ, de Wildt SN, Tibboel D, et al. CKD and hypertension during long-term follow-up in children and adolescents previously treated with extracorporeal membrane oxygenation. Clin J Am Soc Nephrol. 2014;9(12):2070-8.

21. Chaturvedi S, Ng KH, Mammen C. The path to chronic kidney disease following acute kidney injury: a neonatal perspective. Pediatr Nephrol. 2017;32(2):227-41.

22. Askenazi DJ, Feig DI, Graham NM, Hui-Stickle S, Goldstein SL. 3-5 year longitudinal follow-up of pediatric patients after acute renal failure. Kidney Int. 2006;69(1):184-9.

23. Drukker A, Guignard JP. Renal aspects of the term and preterm infant: a selective update. Curr Opin Pediatr. 2002;14(2):175-82.

24. Kastl JT. Renal function in the fetus and neonate-the creatinine enigma. Semin Fetal Neonatal Med. 2017;22(2):83-9.

25. Akcan-Arikan A, Zappitelli M, Loftis LL, Washburn KK, Jefferson LS, Goldstein SL. Modified RIFLE criteria in critically ill children with acute kidney injury. Kidney Int. 2007;71(10):1028-35. 
26. Mehta RL, Kellum JA, Shah SV, Molitoris BA, Ronco C, Warnock DG, et al. Acute Kidney Injury Network: report of an initiative to improve outcomes in acute kidney injury. Crit Care. 2007;11(2):R31.

27. group KDIGOKAKIW. KDIGO clinical practice guidelines for acute kidney injury. Kidney Int. 2012;Suppl 2(1):1-138.

28. Zappitelli M, Ambalavanan N, Askenazi DJ, MoxeyMims MM, Kimmel PL, Star RA, et al. Developing a neonatal acute kidney injury research definition: a report from the NIDDK neonatal AKI workshop. Pediatr Res. 2017;82(4):569-73.

29. Durkan AM, Alexander RT. Acute kidney injury post neonatal asphyxia. J Pediatr. 2011;158(2 Suppl):e29-33.

30. Doyle JF, Forni LG. Update on sepsis-associated acute kidney injury: emerging targeted therapies. Biologics. 2016;10:149-56.

31. Matejovic M, Chvojka J, Radej J, Ledvinova L, Karvunidis T, Krouzecky A, et al. Sepsis and acute kidney injury are bidirectional. Contrib Nephrol. 2011;174:78-88.

32. Zappitelli M, Selewski DT, Askenazi D. Nephrotoxic medication exposure and acute kidney injury in neonates. NeoReviews. 2012;13(7):e420.

33. Hanna MH, Askenazi DJ, Selewski DT. Drug-induced acute kidney injury in neonates. Curr Opin Pediatr. 2016;28(2):180-7.

34. Lopez-Novoa JM, Quiros Y, Vicente L, Morales AI, Lopez-Hernandez FJ. New insights into the mechanism of aminoglycoside nephrotoxicity: an integrative point of view. Kidney Int. 2011;79(1):33-45.

35. Elyasi S, Khalili H, Dashti-Khavidaki S, Mohammadpour A. Vancomycin-induced nephrotoxicity: mechanism, incidence, risk factors and special populations. A literature review. Eur J Clin Pharmacol.

2012;68(9):1243-55.

36. Bianchetti MG, Roduit C, Oetliker OH. Acyclovirinduced renal failure: course and risk factors. Pediatr Nephrol. 1991;5(2):238-9.

37. Gunness P, Aleksa K, Bend J, Koren G. Acyclovirinduced nephrotoxicity: the role of the acyclovir aldehyde metabolite. Transl Res. 2011;158(5):290-301.

38. Zager RA, Bredl CR, Schimpf BA. Direct amphotericin Bmediated tubular toxicity: assessments of selected cytoprotective agents. Kidney Int. 1992;41(6):1588-94.

39. Antonucci R, Fanos V. NSAIDs, prostaglandins and the neonatal kidney. J Matern Fetal Neonatal Med. 2009;22(Suppl 3):23-6.

40. Lindle KA, Dinh K, Moffett BS, Kyle WB, Montgomery NM, Denfield SD, et al. Angiotensin-converting enzyme inhibitor nephrotoxicity in neonates with cardiac disease. Pediatr Cardiol. 2014;35(3):499-506.

41. Pandey V, Kumar D, Vijayaraghavan P, Chaturvedi T, Raina R. Non-dialytic management of acute kidney injury in newborns. J Renal Inj Prev. 2017;6(1):1-11.

42. Prins I, Plotz FB, Uiterwaal CS, van Vught HJ. Low-dose dopamine in neonatal and pediatric intensive care: a systematic review. Intensive Care Med.

2001;27(1):206-10.
43. Toth-Heyn P, Drukker A, Guignard JP. The stressed neonatal kidney: from pathophysiology to clinical management of neonatal vasomotor nephropathy. Pediatr Nephrol. 2000;14(3):227-39.

44. Arikan AA, Zappitelli M, Goldstein SL, Naipaul A, Jefferson LS, Loftis LL. Fluid overload is associated with impaired oxygenation and morbidity in critically ill children. Pediatr Crit Care Med. 2012;13(3):253-8.

45. Koyner JL, Davison DL, Brasha-Mitchell E, Chalikonda DM, Arthur JM, Shaw AD, et al. Furosemide stress test and biomarkers for the prediction of AKI severity. J Am Soc Nephrol. 2015;26(8):2023-31.

46. Thompson K, Flynn J, Okamura D, Zhou L. Pretreatment of formula or expressed breast milk with sodium polystyrene sulfonate (Kayexalate $(\mathrm{R}))$ ) as a treatment for hyperkalemia in infants with acute or chronic renal insufficiency. J Ren Nutr. 2013;23(5):333-9.

47. Parkhouse HF, Barratt TM, Dillon MJ, Duffy PG, Fay J, Ransley PG, et al. Long-term outcome of boys with posterior urethral valves. Br J Urol. 1988;62(1):59-62.

48. Deshpande AV. Current strategies to predict and manage sequelae of posterior urethral valves in children. Pediatr Nephrol. 2017.

49. Ronco C, Garzotto F, Brendolan A, Zanella M, Bellettato $M$, Vedovato $S$, et al. Continuous renal replacement therapy in neonates and small infants: development and first-in-human use of a miniaturised machine (CARPEDIEM). Lancet. 2014;383(9931):1807-13.

50. Kaddourah A, Goldstein SL. Renal replacement therapy in neonates. Clin Perinatol. 2014;41(3):517-27.

51. Askenazi DJ, Goldstein SL, Koralkar R, Fortenberry J, Baum M, Hackbarth R, et al. Continuous renal replacement therapy for children $</=10 \mathrm{~kg}$ : a report from the prospective pediatric continuous renal replacement therapy registry. J Pediatr. 2013;162(3):587-92.e3

52. Hakan N, Aydin M, Zenciroglu A, Aydog O, Erdogan D, Karagol BS, et al. Acute peritoneal dialysis in the newborn period: a 7-year single-center experience at tertiary neonatal intensive care unit in Turkey. Am J Perinatol. 2014;31(4):335-8.

53. Alparslan C, Yavascan O, Bal A, Kanik A, Kose E, Demir $\mathrm{BK}$, et al. The performance of acute peritoneal dialysis treatment in neonatal period. Ren Fail. 2012;34(8):1015-20.

54. Coulthard MG, Crosier J, Griffiths C, Smith J, Drinnan M, Whitaker M, et al. Haemodialysing babies weighing $<8 \mathrm{~kg}$ with the Newcastle infant dialysis and ultrafiltration system (Nidus): comparison with peritoneal and conventional haemodialysis. Pediatr Nephrol. 2014;29(10):1873-81.

55. Askenazi D, Ingram D, White S, Cramer M, Borasino S, Coghill C, et al. Smaller circuits for smaller patients: improving renal support therapy with Aquadex. Pediatr Nephrol. 2016;31(5):853-60.

56. Axelrod DM, Anglemyer AT, Sherman-Levine SF, Zhu A, Grimm PC, Roth SJ, et al. Initial experience using aminophylline to improve renal dysfunction in the pediatric cardiovascular ICU. Pediatr Crit Care Med. 2014;15(1):21-7. 
57. Raina A, Pandita A, Harish R, Yachha M, Jamwal A. Treating perinatal asphyxia with theophylline at birth helps to reduce the severity of renal dysfunction in term neonates. Acta Paediatr. 2016;105(10):e448-51.

58. Harer HR AD, Boohaker L, Carmody JB,. Griffin RL, Guillet R Selewski DT SJ, Charlton JR, on behalf of the Neonatal Kidney Collaborative (NKC). Early caffeine administration in preterm neonates reduces the risk of acute kidney injury: results from the AWAKEN study JAMA Pediatrics. 2018;Accepted for publication.

59. Kwiatkowski DM, Axelrod DM, Sutherland SM, Tesoro TM, Krawczeski CD. Dexmedetomidine is associated with lower incidence of acute kidney injury after congenital heart surgery. Pediatr Crit Care Med. 2016;17(2):128-34.

60. Khajuria A, Tay C, Shi J, Zhao H, Ma D. Anesthetics attenuate ischemia-reperfusion induced renal injury: effects and mechanisms. Acta Anaesthesiol Taiwan. 2014;52(4):176-84.

61. Hughes JM, Beck TR, Rose CE Jr, Carey RM. The effect of selective dopamine-1 receptor stimulation on renal and adrenal function in man. J Clin Endocrinol Metab. 1988;66(3):518-25.

62. Ricci Z, Luciano R, Favia I, Garisto C, Muraca M, Morelli $\mathrm{S}$, et al. High-dose fenoldopam reduces postoperative neutrophil gelatinase-associated lipocaline and cystatin $\mathrm{C}$ levels in pediatric cardiac surgery. Crit Care. 2011;15(3):R160.

63. Ando M, Park IS, Wada N, Takahashi Y. Steroid supplementation: a legitimate pharmacotherapy after neonatal open heart surgery. Ann Thorac Surg. 2005;80(5):1672-8. discusison 8

64. Robert SM, Borasino S, Dabal RJ, Cleveland DC, Hock $\mathrm{KM}$, Alten JA. Postoperative hydrocortisone infusion reduces the prevalence of low cardiac output syndrome after neonatal cardiopulmonary bypass. Pediatr Crit Care Med. 2015;16(7):629-36.

65. Billings FT, Petracek MR, Roberts LJ 2nd, Pretorius M. Perioperative intravenous acetaminophen attenuates lipid peroxidation in adults undergoing cardiopulmonary bypass: a randomized clinical trial. PLoS One. 2015;10(2):e0117625.

66. Hobbs DJ, Steinke JM, Chung JY, Barletta GM, Bunchman TE. Rasburicase improves hyperuricemia in infants with acute kidney injury. Pediatr Nephrol. 2010;25(2):305-9.

67. Sasser WC, Dabal RJ, Askenazi DJ, Borasino S, Moellinger AB, Kirklin JK, et al. Prophylactic peritoneal dialysis following cardiopulmonary bypass in children is associated with decreased inflammation and improved clinical outcomes. Congenit Heart Dis.

2014;9(2):106-15.

68. Bokesch PM, Kapural MB, Mossad EB, Cavaglia M, Appachi E, Drummond-Webb JJ, et al. Do peritoneal catheters remove pro-inflammatory cytokines after cardiopulmonary bypass in neonates? Ann Thorac Surg. 2000;70(2):639-43.

69. Dittrich S, Aktuerk D, Seitz S, Mehwald P, SchulteMonting J, Schlensak C, et al. Effects of ultrafiltration and peritoneal dialysis on proinflammatory cytokines during cardiopulmonary bypass surgery in newborns and infants. Eur J Cardiothorac Surg. 2004;25(6):935-40.

70. Gassanov N, Nia AM, Caglayan E, Er F. Remote ischemic preconditioning and renoprotection: from myth to a novel therapeutic option? J Am Soc Nephrol. 2014;25(2):216-24.

71. Boehne M, Jack T, Koditz H, Seidemann K, Schmidt F, Abura $\mathrm{M}$, et al. In-line filtration minimizes organ dysfunction: new aspects from a prospective, randomized, controlled trial. BMC Pediatr. 2013;13:21.

72. Joshi MS, Montgomery KA, Giannone PJ, Bauer JA, Hanna MH. Renal injury in neonates: use of "omics" for developing precision medicine in neonatology. Pediatr Res. 2017;81(1-2):271-6.

73. Hanna MH, Dalla Gassa A, Mayer G, Zaza G, Brophy PD, Gesualdo L, et al. The nephrologist of tomorrow: towards a kidney-omic future. Pediatr Nephrol. 2017;32(3):393-404.

74. Nguyen MT, Devarajan P. Biomarkers for the early detection of acute kidney injury. Pediatr Nephrol. 2008;23(12):2151-7.

75. Decramer S, Zurbig P, Wittke S, Mischak H, Bascands JL, Schanstra JP. Identification of urinary biomarkers by proteomics in newborns: use in obstructive nephropathy. Contrib Nephrol. 2008;160:127-41. 